\title{
Amarjit Singh Chahal, Medallist of the International Society of Paraplegia 1993
}

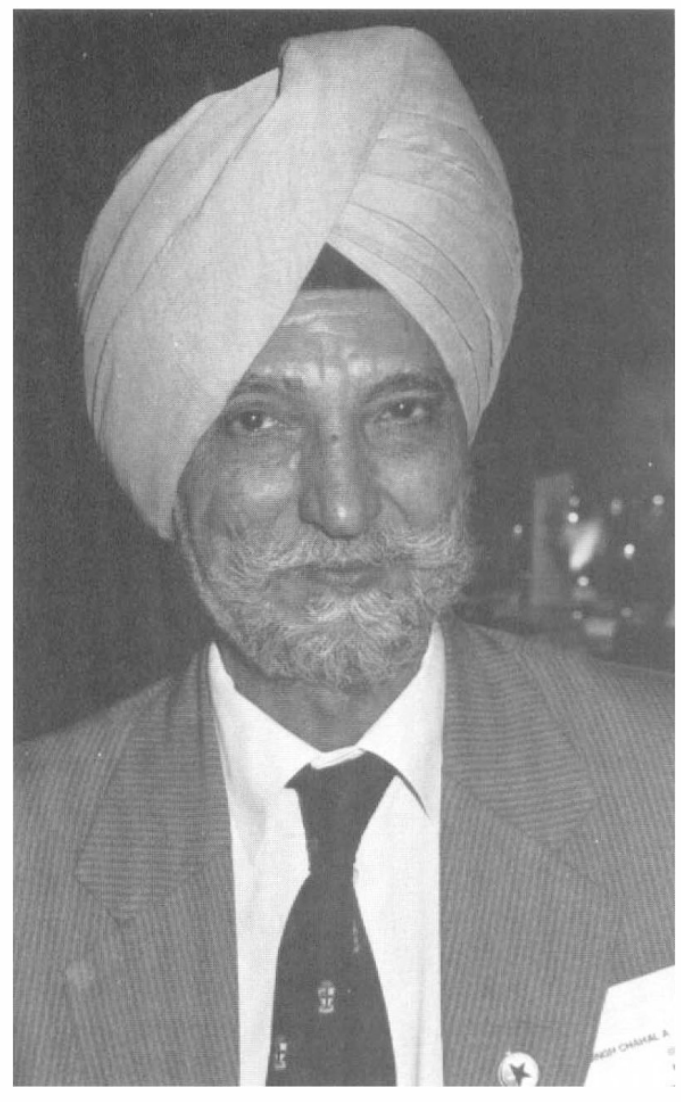

Dr Chahal obtained his MBBS from the Government Medical College, Amritsar, India in November 1951, completing his examinations with great credit and being placed second in the graduation class at the university. He then served as house surgeon in the Department of Surgery, and next worked as a casualty surgeon. After this he joined the Armed Forces Medical Services as a captain. In 1957 he was selected for training in advanced surgery and qualified as a surgeon in October 1958, being placed first in his qualifying course.

Dr Chahal was then posted as a surgeon to a forward surgical unit in Kashmir and in 1965 was the surgeon-in-charge of a mobile field hospital in Punjab in the Indo-Pakistan war. During this period he worked tirelessly and is recorded as having operated on 238 patients in just 22 days. He was reminded of the special needs of patients with spinal cord injury when he was called upon to treat 22 casualities with paraplegia with no proper facilities for rehabilitation.

Major General P T Joseph, Chief. Surgeon, then selected Major Chahal for training in the specialty of spinal cord injury and posted him as a surgeon in charge of the Artificial Limb Centre in Pune in November 1966. He was then responsible for the rehabilitation of a large number of amputee and paraplegic casualties as well as children with postpolio deformities.

In 1968 Sir Ludwig Guttmann visited Pune for two days and observed the facilities at the Military Hospital. Sir Ludwig indicated to General Joseph that he should send Dr Chahal to Perth in Western Australia for training in the specialty of spinal cord injury under the guidance of Sir George Bedbrook. Sir Ludwig felt that it was in the interest of the armed forces of India to have this training in Australia rather than to travel to England.

From January 1970 to November 1970 he worked in the Spinal Injuries Centre, Royal Perth Rehabilitation Hospital with Sir George, the medical director of this unit. He passed the fellowship of the Royal Australasian College of Surgeons in October 1970 and then continued his postgraduate training in the Spinal Centre in the Austin Hospital, Melbourne with Dr David Cheshire.

From January to November $1971 \mathrm{Dr}$ Chahal worked in the Spinal Injuries Unit at the North Shore Hospital of Sydney with Dr John Yeo, medical director of this unit and Dr John Grant, senior neurosurgeon. He then returned to India and 'took charge' of the Spinal Cord Injury Centre at the Military Hospital, Kirkee, Pune in India continuing the practice of orthopaedics and working as associate professor in the armed forces.

Dr Chahal was elected a member of IMSOP in 1970 while he was continuing postgraduate studies in Australia, and in 1974 he attended the IMSOP meeting at Stoke Mandeville Hospital and gave an 
account of his experiences in 'The Management of Spinal Cord Injuries in the Armed Forces in India'. This presentation gave details of his unique approach to fractures and dislocations of the thoracolumbar spine associated with paraplegia which used continuous traction. The paper was later published in Paraplegia and generated considerable interest, particularly in countries with limited surgical facilities. Air Marshal Chahal also studied at Stoke Mandeville Hospital and with Dr Paeslack in Heidelberg, Germany. He has always generously described these experiences as greatly enriching his knowledge, allowing him to contribute significantly to the development of adequate treatment for patients with spinal cord injuries in the armed forces in India.

In 1978 he was appointed professor of orthopaedics at the Armed Forces Medical College, Pune. He introduced the use of Harrington instrumentation for internal fixation to stabilise fractures and dislocation of the thoracolumbar spine. He was responsible for basic research in lumbar canal stenosis in India.

With his promotion to Brigadier in 1983, he was appointed consultant in orthopaedics at the Base Hospital, Delhi Cantt. In 1984 he was also appointed adviser to the government of India and a member of the board of the Indian Spinal Injuries Centre, Delhi.

In 1985 Professor Chahal organised the first international conference at the Spinal Cord Injury Centre in Delhi, India. From January 1986 he performed duties as deputy director of medical services for the Northern and Southern Army in India and in 1987, as director of medical services, Southern
Army, he organised the medical care of wounded soldiers from the Indian peacekeeping force in Sri Lanka. During this period he was personally involved in the treatment of 24 servicemen who had suffered spinal cord injuries from shelling, mine wounds and accidents in Sri Lanka.

In November 1988 he was appointed director general, Medical Services of the Indian Air Force with the rank of Air Marshal. On his retirement in January 1990, Air Marshal Chahal took over as director of the Indian Spinal Injuries Centre. An excellent team has been appointed to this centre and the unit will now be ready for the treatment of patients by the end of 1993 . This centre will have the distinction of providing an appropriate level of treatment to patients with spinal cord injury and will have available modern equipment such as computerised tomography and magnetic resonance imaging to investigate up to 120 spinal injured and polytrauma patients.

Air Marshal Chahal continues his active interest in spinal injury patients and is now a visiting surgeon to a number of hospitals in Delhi.

All members of IMSOP congratulate Air Marshal Chahal on the great honour of being the 1993 Medallist of the International Medical Society of Paraplegia. Our colleague has achieved greatness through challenges met and overcome, both within and without his remarkable country. 'Amar' Chahal remains as always a warm and generous colleague.

Dr John Yeo AO

NSMC, Sydney, Australia 